\title{
The Role Of Activity-Base Costing In The Development Of Segmented Financial Statements: An Examination
}

George O. Gamble, University of Houston, USA

John E. Simms, University of St. Thomas, USA

\begin{abstract}
The recent financial crisis has brought into question a number of the qualities and characteristics of current financial reporting practices. One of the areas in question is that of reporting segmental information in relation to "paper" gains and losses. In this paper, Activity is divided between economic and financial activities. We bring to the fore some of the historical sources of the principles on which segmental reporting is based, and then propose an alternative reporting scheme along the lines of activity-based costing. The advantages and shortcomings of the proposed system are examined and the implications of the use of the system are discussed.
\end{abstract}

Keywords: activity-based costing, paper gains and losses, financial reporting

\section{INTRODUCTION}

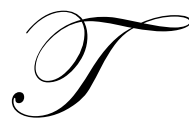

he Financial Accounting Standards Board (FASB) addressed the segment reporting issue with the issuance of SFAS No. 14, "Financial Reporting for Segments of a Business Enterprise".(FASB, 1976). The objective of the statement is to aid current and future investors and creditors in their assessment of a corporate entity's past performance and future prospects. To date, SFAS No. 14 has not ended the controversy concerning the segment reporting issue. For example, in a recent article in Forbes (1990) Wechsler and Wandycz made the following comment: "Since 1976, companies have been required to tell shareholders how each of their business segments is doing. Unfortunately, the disclosures are often meaningless" (p.126). Dissatisfaction with SFAS No. 14 also stems from the fact that it gives management a tremendous amount of flexibility in many segment reporting issues, such as what constitutes a segment and cost allocation. Another reason for dissatisfaction centers on the need of external decision makers to receive disaggregated information so that a proper evaluation can be made regarding the long term effects of management's decisions on such matters as right sizing, mergers and acquisitions, and creative financing arrangements and/or agreements.

The objective of this paper is to develop an alternative reporting scheme for segments. The scheme developed will attempt to incorporate the activity based costing (ABC) model. In contemporary accounting research, $\mathrm{ABC}$ systems have recently received increased attention as an alternative to traditional cost accounting systems. Current researchers argue that traditional cost systems systematically distort product costs (see, for example, Cooper and Kaplan, 1988). Furthermore, many suggest that traditional cost systems are not particularly helpful in managing activities and that $\mathrm{ABC}$ can benefit management in managing activities as well as in product costing. Because of these benefits, many corporate entities are in the process of switching from traditional cost systems to some type of $\mathrm{ABC}$ system.

The next section of the paper provides a description of present segment reporting requirements and the major weaknesses associated with the employment of such requirements. Next, ABC will be presented along with its relationship to segmental reporting. Finally, the proposed segmented financial statements will be presented along with a discussion of their benefits. 


\section{CONTEMPORARY SEGMENTAL REPORTING REQUIREMENTS}

According to SFAS No. 14, the first step in segmental reporting is the identification of industry segments. An industry segment is defined as "a component of an enterprise engaged in providing a product or service or a group of related products and services primarily to unaffiliated customers ... for a profit" (par. 10). After the selection of industry segments, the next step is the determination of reportable industry segments. A reportable industry segment is an industry segment or group of closely related industry segments for which information is required to be reported. An industry segment is reportable if it satisfies one of the following tests:

a. Its revenue (including both sales to unaffiliated customers and intersegment sales or transfers) is 10 percent or more of the combined revenue (sales to unaffiliated customers and intersegment sales or transfers) of all of the enterprise's industry segments.

b. The absolute amount of its operating profit or operating loss is 10 percent or more of the greater, in absolute amount, of:

(i) The combined operating profit of all industry segments that did not incur an operating loss, or

(ii) The combined operating loss of all industry segments that did incur an operating loss.

c. Its identifiable assets are 10 percent or more of the combined identifiable assets of all industry segments (SFAS No. 14, par.15).

The operating profit or loss of an industry segment is its revenue minus all operating expenses. Operating expenses include expenses:

that relate to both revenue from sales to unaffiliated customers and revenue from intersegment sales or transfers; those operating expenses incurred by an enterprise that are not directly traceable to an industry segment shall be allocated on a reasonable basis among those industry segments for whose benefit the expenses were incurred ... (SFAS No. 14, par. 10).

The reportable segments determined must represent a substantial portion of the enterprise's total operation. If the combined revenue from sales to unaffiliated customers of all reportable segments is less than 75 percent of the combined revenue from sales to unaffiliated customers of all industry segments, additional segments must be identified as reportable segments to bring the total up to 75 percent. Similarly, if the number of reportable segments is more than ten, it may be appropriate for the enterprise to combine the most closely related industry segments into broader reportable segments.

The following information is disclosed for each reportable segment:

- With respect to revenue: (1) the amount of revenue from unaffiliated and affiliated customers, (2) a reconciliation of the amounts of revenue from all reportable segments with revenue reported in the income statement of the enterprise, and (3) the basis of accounting for intersegment sales and transfers.

- With respect to assets: (1) aggregate carrying amount of identifiable assets, and (2) a reconciliation of identifiable assets for all reportable segments and other industry segments with total consolidated assets (corporate assets are to be identified separately in the reconciliation).

- With respect to profitability: (1) the amount of operating profit or loss, (2) the nature and amount of unusual or infrequency occurring items for each reportable segment, (3) reconciliation of operating profit or loss for all reportable segments and other industry segments with pretax income from continuing operations as reflected in the consolidated income statement (corporate expenses are to be disclosed separately), (4) effect on operating profit or loss of reportable segments of any changes in allocating operating expenses among segments, and (5) effect on operating profit of each reportable segment of a change in accounting principle.

\section{DEFICIENCIES IN PRESENT PRACTICE}

One of the major deficiencies associated with contemporary segmental reporting is the aggregated nature of the information reported concerning the results of operations and the balance sheet. With regard to the results of 
operations, the aggregated nature of the data and the way in which it is displayed do not provide external decision maker with the type of information needed to properly evaluate segmented operations along two important dimensions - space and time. ${ }^{1}$ Space and time are important because decision makers should want to know the individual revenue and expense amounts that are mutually exclusive with regard to each segment and reporting period under investigation. The way in which revenue and operating expenses are defined is also a problem area. The inclusion of intersegment sales or transfers in the definition of segment revenue and the inclusion of expenses that relate to those intersegment sales or transfers in the definition of operating expenses are confusing and provide little to no information to investors and creditors in terms of disclosing actual revenue and operating expenses of a segment. ${ }^{2}$

The balance sheet suffers from an aggregation problem because investors are not provided with the level of information that would allow them to assess the dollar amount invested in individual assets. Further, because liability and capital stock information are not presented for each reportable segment, financial statement users are not provided with enough information to evaluate individual financing risk.

Another major deficiency associated with the present reporting scheme is the way in which revenues, expenses, and assets are classified. Presently, a distinction is not drawn between financial and economic balances. This distinction is necessary in order to account separately for the two major activities of corporate entities. First, corporate entities are organized for the primary purpose of providing economic goods and services. This function is described as operating in nature; related activities are generally described as the production of economic goods and services. Second, corporate entities engage in financing activities to acquire economic resources and to finance the production of economic goods and services of other corporate entities.

Finally, the contemporary reporting scheme provides management with too many choices in its determination of reportable segments and the allocation basis for joint $\operatorname{cost}(\mathrm{s})$. Prior research has reported that managers' accounting choices are systematically affected by firm contracts based explicitly on accounting numbers (for example, management compensation plans and corporate bond covenants) and situations which implicitly use accounting numbers (Holthausen and Leftwich 1983; Watts and Zimmerman 1986). Further, an enterprise's political sensitivity, frequently measured by firm size, appears to affect managers' accounting decisions even though accounting numbers are used only implicitly in the political process (Christie 1990). Thus, allowing management the freedom of too many choices may not lead to making the best choice in the interest of investors and creditors.

\section{ACTIVITY-BASED COSTING}

$\mathrm{ABC}$ refers to the basis for cost accumulation, either direct or indirect, to products or services. The traditional approach to assigning costs to products is to attach those costs that are directly traceable to the product and allocate the indirect costs by a measure of volume, such as direct labor hours, direct labor dollars, or machine hours. $\mathrm{ABC}$, on the other hand, requires cost pools for each defined activity. Costs are attached to only those products that pass through the activity. Indirect costs which cannot be traced to each unit of product are allocated on the basis of cost drivers, which are responsible for the variability of the activity. The concept underlying $\mathrm{ABC}$ systems is a simple one that rests on the premise that products utilize activities and activities utilize resources. That is, the cost of a product equals the cost of the raw materials plus the sum of the cost of all the activities required to produce that product. Thus, $\mathrm{ABC}$ systems trace costs to activities and then to products. Hence, an entity's operating expenses are assigned to outputs based on the activities performed for these outputs.

The following elements are important to ABC systems: (1) define the process. Trace the flow of inputs and outputs through each step of the process for each product or service, (2) analyze the activities in the process, that is, identify the activities through which the product or service flow and separate the activities from traditional departments, (3) establish cost pools and match them with the defined activities so that each activity has its own identifiable cost pool for allocation, and (4) analyze each activity to determine its cost driver. Activity centers use separate activity cost drivers (an assignment or allocation base) for each activity. The activity cost drivers are not devices to allocate costs. They represent the demands that outputs make on each activity. For example, the activity cost driver for processing purchase orders could be the number of purchase orders. Thus, while some activity cost drivers are unit-related, e.g., machine and labor hours, many activity cost drivers are batched-related, order-related 
product andlor customer sustaining (Cooper and Kaplan, 1991, p.132). Hence, ABC identifies additional cost drivers by identifying additional activities on which to base the allocation of manufacturing costs to products. This identification of additional cost drivers results in a more precise allocation of product costs. One reason for this increased precision is that additional costs are identified, i.e., costs which were classified as fixed costs under the traditional system, and reclassified as allocable variable costs. Another possible reason for the increased precision is that an allocation base which is proportional with the allocable manufacturing costs is being used. As a result, more accurate product costs should be obtained (Cooper and Kaplan, 1992, p.2).

The above discussion reveals the fact that $\mathrm{ABC}$ is concerned with the allocation of common costs on a basis that is consistent with output and the traditional costs allocation schemes allocate costs on an input basis. Research results have been mixed regarding which scheme provides more accurate cost estimates. For example, Foster and Gupta (1990) using data obtained from 37 plants of a single manufacturing firm found that most of the volume-related measures of output were highly correlated with manufacturing. However, because only a few measures of manufacturing complexity and efficiency were highly correlated with manufacturing overhead, one is left with the impression that systems based on just volume may not significantly distort information for decision purposes. On the other hand, Banker and Johnston (1993) found that while output capacity and volume are important cost drivers, operations-based driver related to product diversity and production process complexity are also significant in a major service industry. Thus, the results appear to be inconclusive regarding whether an input or output driven cost allocation scheme will lead to better product cost estimates.

\section{RELATIONSHIP BETWEEN ABC AND SEGMENTAL REPORTING}

Both $\mathrm{ABC}$ and segmental reporting are concerned with the accumulation of cost based upon a definition of an activity under observation. With respect to $\mathrm{ABC}$, the activity under observation is typically a process that has the capacity to produce a number of homogenous or heterogenous products and services. ABC also provides decisionmakers with a tool that can be used to evaluate or determine an approximate total cost incurred to produce each product or batch of products or the approximate total cost incurred to provide a service. ABC also can be employed to measure unused capacity (Cooper and Kaplan, 1992, p3.). Unused capacity is calculated in the following manner:

Cost of Activity Supplied $=$ Cost of Activity Used + Cost of Unused Activity

In terms of financial statement presentation, used and unused resources are separately disclosed. Cooper and Kaplan (1992) are of the opinion that the resource usage information can be used by managers to:

monitor and predict the changes in demand for activities as a function of changes in output volume and mix, process changes and improvements, introduction of new technology, and changes in product and process design. As such changes are contemplated, managers can predict where either shortages or excesses of capacity will occur. The managers can then either modify their decisions so that activity demand will be brought into balance with activity supply, or they can change the level of activities to be supplied in forthcoming periods ( $p .3$ ).

Segmental reporting, on the other hand, is concerned with a larger activity dimension. It not only focuses on production and service activities, but financing, investment, and operating activities as well. More specifically, segmental reporting is concerned with providing investors and creditors with an evaluation of a number of activities, contained in several financial statements, for each segment over a period of time. As such, for income statement purposes, it is important that we define the nature of expenses in the context of the segment (space) and the time period (time) over which an evaluation must be made. The expense recognition principle guides the amount of expenses recognized for the reporting period and how a corporate entity defines a segment determines the dollar amount assigned to each segment. Consequently, it is important that we further evaluate expenses in the context of both time and space.

With regard to the temporal dimension of a corporate entity, it is important that a distinction is drawn between variable and fixed expenses. This distinction is important for period evaluation because investors and creditors should want to know the difference between those expenses that are intricately related to and inseparable from the period under observation (variable) and those that are common (joint) with regard to several time periods. 
For spatial evaluation, a differentiation between direct and common (joint) expenses is also important because investors and creditors should want to know the difference between those expenses that are intricately related to and inseparable from the segment (direct) and those that are common (joint) with respect to several segments.

In summary, $\mathrm{ABC}$ is a tool that management can use to allocate joint costs, determine actions that will likely have the greatest impact on profits, and provide information regarding other resource allocation issues. In terms of the allocation of joint costs, it treats all costs as if they were variable. However, for segmental reporting purposes it is important to have both variable and common (joint) costs presented. The concept of multiple cost drivers is important to both $\mathrm{ABC}$ and segmental reporting. $\mathrm{ABC}$ uses cost drivers to treat joint costs as if they were variable and segmental reporting employs them to treat joint costs as if they were joint. In terms of matching, both use output as an independent variable and input as a dependent variable. However, they are at variance with regard to the definition for output. $\mathrm{ABC}$ defines output in terms of the production process and segmental reporting in terms of revenue. Consequently, $A B C$ 's definition of an activity is much too narrow for that which is needed for the preparation of segmented financial statements.

Based upon the above observations, it appears that $\mathrm{ABC}$ is not appropriate for segmented financial statements. However, it could be used in the development of supplementary information to accompany the segmented statements. For example, the disclosure of unused capacity for each segment and any other information that management would like to present regarding the product(s) and/or production process(es) of the segments. Any costs allocation scheme which attempts to allocate common costs is inappropriate for segmented financial statements. As was stated above, the financial statements presented should allow investors and creditors an opportunity to evaluate spatial and temporal dimension of a corporate entity in a meaningful manner. Meaningful in the sense that costs are presented in a homogenous fashion ${ }^{3}$ which allows external decision makers an opportunity to evaluate each segment on its own merits. Further, if needed for individual decision model purposes, decision makers can employ whatever allocation scheme is deemed appropriate.

\section{PROPOSED SEGMENTED FINANCIAL STATEMENTS}

Exhibit 1 contains the proposed income statement. As was previously stated, segmental reporting is concerned with an evaluation of the different segments of a corporate entity over a period of time. As such, it is important that we define the nature of revenue and expenses in the context of the segment (space) and the time period over which an evaluation must be made. The revenue recognition principle guides the amount of revenue recognized for the reporting period and the way in which an entity defines a segment will dictate the dollar amount assigned to each segment. The expense recognition principle guides the amount of expenses recognized for the reporting period and, just like revenue, the definition of a segment will determine the dollar amount assigned to each segment.

First a distinction is drawn between economic and financial revenue. As was previously stated, this distinction is necessary in order to account separately for the two major activities of corporate entities. Second, a distinction between direct and indirect variable cost is also drawn. This distinction is necessary for period and segment evaluation. Direct variable is separate with respect to both space and time and indirect variable is common with respect to space and separate with respect to time.

Similar to the presentation of revenue, a distinction is drawn between economic and financial balances. The only expenses that are assigned to a segment is direct variable. This treatment of direct variable expenses specifically, and total expenses in general, is consistent with the logic associated with the development of segmented financial statements, i.e., each segment exist because of its ability to contribute to the overall profitability of a corporate entity. The common expenses, both variable and fixed are shown on a total basis.

Exhibit 2 contains the proposed segmented balance sheet. As with the segmented income statement, a distinction is drawn between financial and economic assets. Further, each segment is assigned the assets, liabilities and equity ${ }^{4}$ employed in its separate operations. 
Exhibit 1: Illustration of Proposed Segmented Income Statement

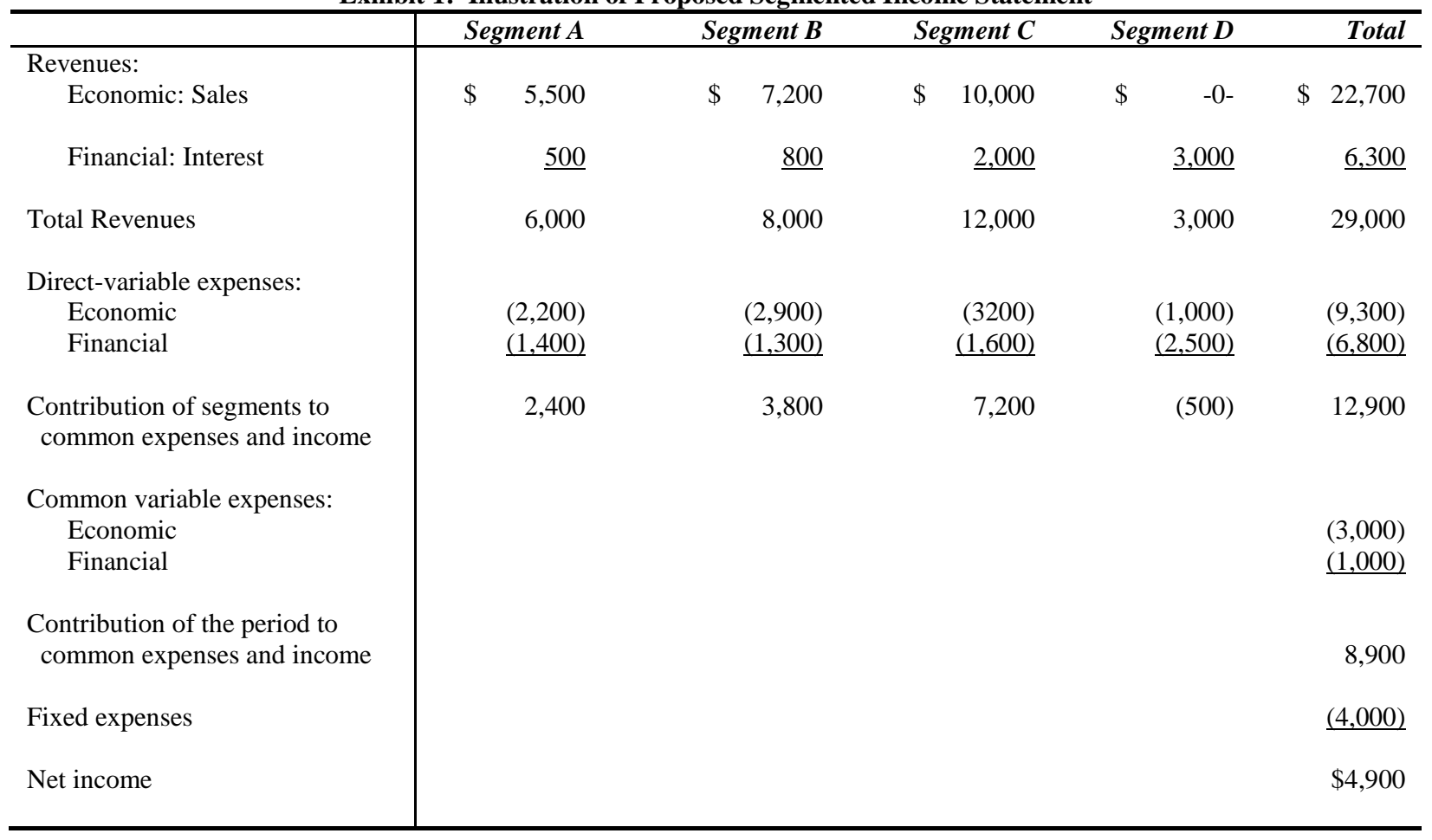

Exhibit 2: Illustration of Proposed Segmented Balance Sheet

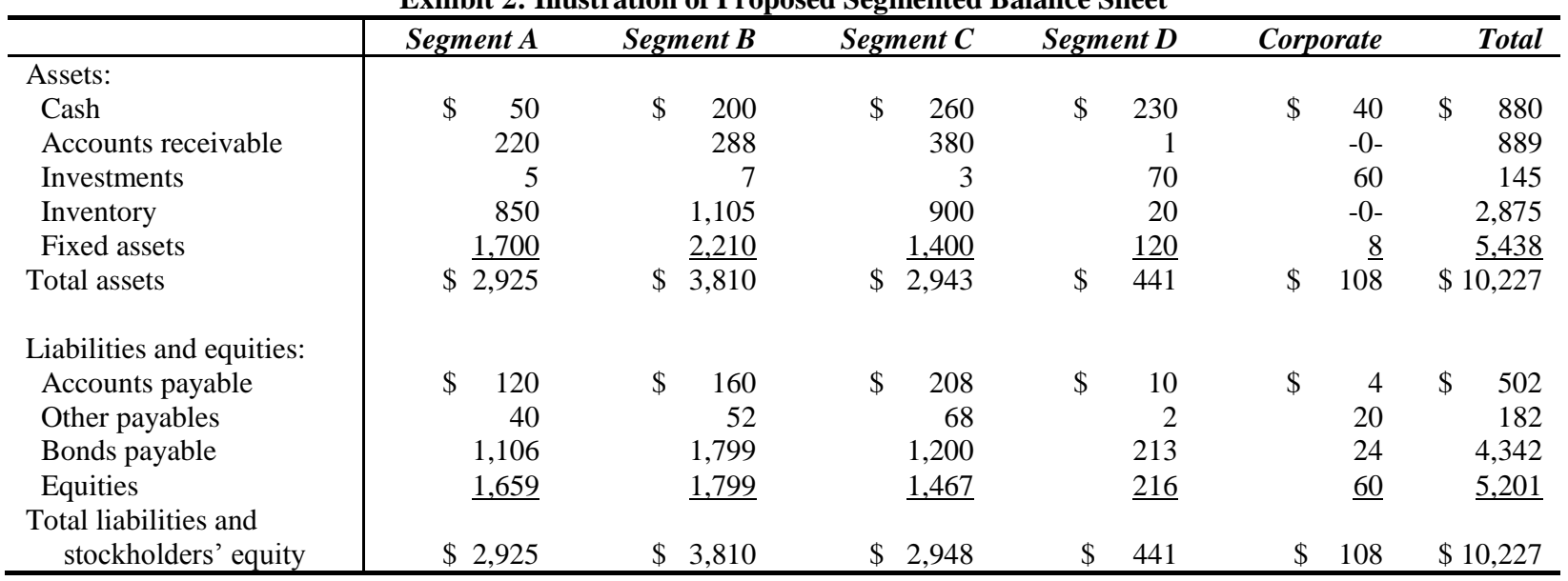

\section{EVALUATIVE ANALYSIS OF PROPOSED SEGMENTED FINANCIAL STATEMENTS}

The amount of detailed information disclosed concerning each segment emphasizes management's need to diversify operations so that risks can be minimized. Consequently, one could say that a corporate entity's segments is its portfolio. Thus, investors and creditors need information that will allow them to analyze that portfolio. Portfolio analysis emphasizes the fact that efficient diversification involves combining investments with less than perfect positive correlation in order to reduce risk in the portfolio without sacrificing any of the portfolio's return. As Markowitz (1952, p.89) states it: 
Not only does [portfolio analysis] imply diversification, it implies the "right kind" of diversification for the "right reason." The adequacy of diversification is not thought by investors to depend on the number of different securities held. A portfolio with sixty different railway securities, for example, would not be as well diversified as the same size portfolio with some railroad, some public utility, mining, various sorts of manufacturing, etc.

The proposed balance sheet will provide investors and creditors with the following additional information that should allow them to:

1. Assess leverage and financing risk in a more meaningful manner because the debt and equity employed by each segment is separately disclosed.

2. Assess liquidity measures, e.g., accounts receivable and inventory turnovers, current ratio, and acid test, in a more meaningful manner because they will be able to identify those segments that are more/less liquid than others and, over time, management's corrective action(s). Corrective action(s) could be in the form of improvements in such areas as marketing, customer credit and collection policies, and production and inventory policies.

3. Assess the relative mix (within and among segments) of economic and financial assets over time. This type of information is important because it should enable users to analyze management's action(s) regarding the relative mix of economic and financial assets selected to provide the desired rate of return, over time. ${ }^{5}$

4. Assess the impact of changes in a corporate entity's environment on a holistic basis. This occurs because, for each period presented, investors and creditors are provided with the portfolio of assets that management is of the opinion is important to its survival. Further, this information also should enable them to analyze the changes in the composition of segment assets, liabilities, equity, revenue and expenses as they relate to changes in the environment. allow them to:

With respect to the income statement, investors and creditors are provided with information that should

1. Assess the relative contribution of economic and financial revenue to overall profitability.

2. Assess the relative contribution of each segment to the recovery of common costs and net income. This is important because investors and creditors will be able to separately evaluate the return from each segment and its contribution to overall profitability. Further, as a result of providing this information they also will be in a position to evaluate individual segment risk. ${ }^{6}$

3. Assess the impact of management's decision to diversity into related or unrelated businesses on operating risk. $^{7}$

4. Assess profitability measures, e.g., return-on-assets, return-on-equity, return-on-operating assets, sales-tofixed assets, in a more meaningful manner because the relative contribution of each segment can be determined and, over time, the actions that management have taken to improve those measures. Management action could be in the form of redistributing resources between the segments and classes of assets (economic or financial).

5. Predict future cash flows in a more precise manner. This occurs because direct flows are separated from indirect flows which means that decision-makers are provided with a better gauge for the direct cash flow affect of transactions.

The proposed reporting scheme has been developed in a manner that is consistent with the research studies that have found that segmental information is better for ratio analysis (Amit and Livnat, 1990), the impact that diversification has on capital structure and systematic risk (Amit and Livnat, 1988), and geographic segment data enhance predictive ability for annual income and sales (Balakrishnan, et. al., 1990). The proposed treatment of common costs eliminates the need for management to arbitrarily assign common costs to segments. Further the financial statements presented are different than traditional contribution margin statements because only direct variable expenses are included in the contribution margin computation, as oppose to all variable costs. 


\section{CONCLUDING OBSERVATIONS}

We believe that the proposed framework, though not an established part of conventional accounting, will provide relevant information to current and potential investors. With the way in which companies are down sizing, more segmented information is needed by external decision makers so that they can gain a better understanding of the effect that management's actions will and have had on the overall performance of a corporate entity.

$\mathrm{ABC}$ was discussed with regard to its role in the development of segmented financial statements. It was concluded that, although $\mathrm{ABC}$ is a very important tool in the allocation of joint costs to products and services, it is not appropriate for the allocation of joint costs to profit centers because of the extreme amount of subjectivity associated with such an allocation scheme. As Thomas (1975, p.68) has stated it:

... practitioners have honestly believed that allocations are appropriate and have struggled to cope with them, while we academics saddled practitioners ... that requires such assignments, then failed to provide defensible ways for their calculation.

The proposed financial statements were not developed in isolation but instead, were developed in light of empirical findings. Even though the scope of the paper does not include criteria for the development of segments, the ground work for such research can be found in portfolio theory. That is, management's options regarding the determination of segments should be limited to those as defined by portfolio theory. Finally, it is our expectation that the financial statements developed in this paper will cause the accounting profession to seriously consider the relationship between academic research and practice.

\section{AUTHOR INFORMATION}

George Gamble, $\mathrm{PhD}$, is the Grinaker Professor of Accountancy and Taxation at the University of Houston. He has won numerous awards for both theoretical and empirical work in the area of financial reporting and disclosure, and is considered by many to be one of the top theoretical accounting researchers publishing today.

John Simms is an assistant professor at the University of St. Thomas in Houston. His areas of research include ethics, international accounting, and financial reporting.

\section{REFERENCES}

1. Amit, R. and J. Livnat. 1988. Diversification, capital structure and systematic risk: an empirical investigation., Journal of Accounting,Auditing, \& Finance (Fall): 19-48.

2. _ _ 1990. Grouping of conglomerates by their segments' economic attributes: towards a more meaningful ratio analysis. Journal of Business Finance \& Accounting (Spring): 85-100.

3. Balakrishnan, Ramji, Trevor S. Harris and Pradyot K. Sent. 1990. The predictive ability of geographic segment disclosures. Journal of Accounting Research (Autumn): 305-325.

4. Banker, Rajiv D. and Holly H. Johnston. 1993. An empirical study of cost drivers in the U.S. airline industry. The Accounting Review (July): 576-601.

5. Christie, A.A. 1990. Aggregation of test statistics: an evaluation of the evidence on contracting and size hypotheses. Journal of Accounting and Economics 15-36.

6. Cooper, Robin and Robert S. Kaplan. 1988. How cost accounting systematically distorts product costs. Management Accounting (April): 20-27.

7. _. 1992. Activity-based systems: measuring the costs of resource usage. Accounting Horizons (September): 1-15.

8. _ _ 1991. Profit priorities from activity-based costing. Harvard Business Review (May-June): 130-135.

9. Financial Accounting Standards Board. 1976. Financial Reporting for Segments of a Business Enterprise. Statement of Financial Accounting Standards No. 14. FASB.

10. Foster, G. and M. Gupta. 1990. Manufacturing overhead cost driver analysis. Journal Accounting \& Economics (January): 309-37. 
11. Holthausen, Robert W. and Richard W. Leftwich. 1983. The economic consequences of accounting choice: implications of costly contracting and monitoring. Journal of Accounting \& Economics (April): 77-117.

12. Thomas, Arthur L. 1975. The FASB and the allocation fallacy. Journal of Accountancy (November): 65-68.

13. Watts,Ross and Jerold Zimmerman. 1986. Positive Accounting Theory. Englewood Cliffs, NJ. Prentice Hall.

14. Wechsler, Dana and Katarzyna Wandycz. 1990. An innate fear of disclosure. Forbes (February): 126-127. 
NOTES 